\title{
INOVAÇÃO TECNOLÓGICA NO ENSINO DA SEMIOTÉCNICA E SEMIOLOGIA EM ENFERMAGEM NEONATAL: DO DESENVOLVIMENTO À UTILIZAÇÃO DE UM SOFTWARE EDUCACIONAL ${ }^{1}$
}

\author{
Luciana Mara Monti Fonseca², Fernanda dos Santos Nogueira de Góes³, Geovana Magalhães Ferecini", \\ Adriana Moraes Leite ${ }^{5}$, Débora Falleiros de Mello ${ }^{6}$, Carmen Gracinda Silvan Scochi ${ }^{7}$
}

${ }^{1}$ Parte da tese "Semiotécnica e semiologia do recém-nascido pré-termo: desenvolvimento e validação de um software educacional", Escola de Enfermagem de Ribeirão Preto (EERP) da Universidade de São Paulo (USP) em 2007, financiada pela CAPES, FAPESP e CNPq.

${ }^{2}$ Doutora em Enfermagem. Professor Doutor do Departamento de Enfermagem Materno-Infantil e Saúde Pública da EERP/ USP. São Paulo, Brasil. E-mail: lumonti@eerp.usp.br

${ }^{3}$ Doutoranda do Programa de Pós-Graduação Enfermagem em Saúde Pública da EERP/USP. São Paulo, Brasil. E-mail: fersnogueira@usp.br

${ }^{4}$ Doutoranda do Programa de Pós-Graduação Enfermagem em Saúde Pública da EERP/USP. São Paulo, Brasil. E-mail: geovanaferecini@usp.br

${ }^{5}$ Doutora em Enfermagem. Professor Doutor do Departamento de Enfermagem Materno-Infantil e Saúde Pública da EERP/ USP. São Paulo, Brasil. E-mail: drileite@eerp.usp.br

${ }^{6}$ Livre-Docente em Enfermagem. Professor Associado do Departamento de Enfermagem Materno-Infantil e Saúde Pública da EERP/USP. São Paulo, Brasil. E-mail: defmello@eerp.usp.br

${ }^{7}$ Livre-Docente em Enfermagem. Professor Titular do Departamento de Enfermagem Materno-Infantil e Saúde Pública da EERP/USP. São Paulo, Brasil. E-mail: cscochi@eerp.usp.br

RESUMO: As novas tecnologias têm apresentado as inúmeras possibilidades do uso do computador na educação. Assim, objetivamos descrever o processo de desenvolvimento de um software educacional sobre semiotécnica e semiologia do recém-nascido pré-termo. Utilizamos o referencial pedagógico da problematização e a metodologia de desenvolvimento de software de Bernardo. Resulta que o software Semiotécnica e semiologia do recém-nascido pré-termo apresenta tecnologia avançada, informatizada, interativa e com simulações que permitem a aproximação máxima da realidade, apresentando, gradativamente, a complexidade e as especificidades do recém-nascido pré-termo. Por meio de recursos de hipertexto apresenta-se uma série de mídias integradas: fotos, figuras, vídeos e sons. Este software possibilita aos docentes e estudantes vivenciar a inter-relação entre quatro vertentes: o conteúdo de semiotécnica e semiologia do recém-nascido pré-termo, novas abordagens pedagógicas, inovações tecnológicas em educação e utilização da primeira fase do Processo de Enfermagem atribuindo a organização do conteúdo em necessidades humanas básicas.

DESCRITORES: Educação em Enfermagem. Software. Exame físico. Enfermagem neonatal. Prematuro.

\section{TECHNOLOGICAL INNOVATION IN TEACHING SEMIOLOGY AND SEMIOTECHNIQUE IN NEONATAL NURSING: AN EDUCATIONAL SOFTWARE FROM DEVELOPMENT TO USE}

\begin{abstract}
New technologies have presented numerous possibilities for computer use in teaching. As such; we aim to describe the development process of an educational software about Semiology and semiotechnique for preterm newborns. The pedagogical framework of problematization and Bernardo's software development methodology were used. Results showed that the Semiotechnique and Semiology of preterm newborns software presents advanced, computerized, and interactive technology. Its simulations allow for maximum approximation to reality, gradually presenting the complexities and specificities of preterm newborns. Hypertext resources allow us to present a series of integrated media: photos, videos, and sounds. This software permits professors and students to experience the inter-relationship along four aspects: the content of semiology and semiotechnique of preterm newborns; new pedagogical approaches; technological innovations in education; and use of the first phase of the Nursing Process, attributing to content organization in basic human needs.
\end{abstract}

DESCRIPTORS: Education, nursing. Software. Physical examination. Neonatal nursing. Infant, premature. 


\section{INNOVACIÓN TECNOLÓGICA EN LA ENSEÑANZA DE LA SEMIOTÉCNICA Y SEMIOLOGÍA EN ENFERMERÍA NEONATAL: DEL DESARROLLO A LA UTILIZACIÓN DE UN SOFTWARE EDUCACIONAL}

RESUMEN: Las nuevas tecnologías han presentado numerosas posibilidades del uso de la computadora en la educación. Por lo tanto, el objetivo de este estudio es describir el proceso de desarrollo de un software educacional sobre Semiotécnica y semiología del recién nacido prétermino. Se utilizó el referencial pedagógico de la problematización y la metodología de desarrollo de software de Bernardo. El software Semiotécnica y semiología del recién nacido prétermino presenta una tecnología avanzada, informatizada, interactiva y con simulaciones que permiten la aproximación máxima de la realidad, presentando, gradualmente, la complejidad y las especificidades del recién nacido prétermino. Con el uso de recursos de hipertexto, son presentadas una serie de medias: fotos, figuras, vídeos y sonidos. El software posibilita que los docentes y estudiantes experimenten la interrelación entre cuatro vertientes: el contenido de la semiotécnica y semiología del recién nacido prétermino, nuevas aproximaciones pedagógicas, innovaciones tecnológicas en educación, y, utilización de la primera fase del Proceso de Enfermería atribuyendo la organización del contenido en necesidades humanas básicas.

DESCRIPTORES: Educación en enfermería. Programas informáticos. Examen físico. Enfermería neonatal. Prematuro.

\section{INTRODUÇÃO}

Na contemporaneidade, a crescente evolução de tecnologias da informação vem transformando a sociedade. O computador e a consequente ampliação dos seus recursos têm causado modificações profundas em praticamente todas as atividades da sociedade moderna, tais como o trabalho, a educação, a saúde, a arte e a cultura, dentre outras.

$\mathrm{Na}$ educação, as novas tecnologias têm apresentado as inúmeras possibilidades do uso do computador.

O computador na educação tem a finalidade de organizar documentos e tarefas, sistematizar as atividades, ser recurso auxiliar de ensino, como forma de arquivar os recursos utilizados pelo estudante e também como forma de avaliar o aluno. ${ }^{1}$

Ampliando tal perspectiva, consideramos que o computador deve ser utilizado pelo estudante também com a finalidade de construir o próprio conhecimento, transformando e utilizando a máquina como recurso dinâmico e inventivo. $\mathrm{O}$ educador pode dirigir seu trabalho de forma que o estudante utilize o computador não só para receber informações, mas sim para pensar e criar.

O recurso da informática através do uso do computador deve ser utilizado de forma complementar ao professor, o qual não deve ser substituído. O computador dever ser visto como ferramenta auxiliar de ensino. ${ }^{2}$

Na tentativa de garantir uma aprendizagem mais eficiente, a educação tem passado por constantes reformas, aperfeiçoando tecnologias, numa relação pedagógica progressivamente motivadora e interativa. A educação, atualmente, precisa caminhar junto com a informatização, pois são inúmeros os recursos disponíveis por essa tecnologia. ${ }^{3}$
Assim, há necessidade de o ensino superior mudar a ênfase do ensino e aprendizagem, do professor que dirige o ensino de forma passiva, para uma aprendizagem interativa. No ensino tradicional, pouco dinâmico, nem sempre se oferece a experiência de trabalho real e manuseio prático, o que pode ser obtido por meio da instrução por computador. ${ }^{4}$

$\mathrm{Na}$ enfermagem brasileira o desenvolvimento de programas de ensino mediado por tecnologias constitui uma tendência crescente na atualidade e está vinculado às universidades com projetos de pesquisas dirigidos, predominantemente, à formação dos graduandos e educação em saúde da clientela. ${ }^{5}$

Mesmo conhecendo as possibilidades e potencialidades de uso do computador na educação, ainda há, em muitas instituições de ensino e saúde, a escassez de material educacional com os recursos da informática.

Apesar do avanço tecnológico, o ensino de enfermagem no Brasil ainda ocorre, em sua maioria de forma tradicional, ministrando-se aulas formais com exposição dos conteúdos e com pouca participação efetiva dos alunos. Por outro lado, já se observam mudanças em face às novas diretrizes do ensino superior. Neste contexto, consideramos que o desenvolvimento de softwares educacionais pode contribuir com um ensino mais participativo disponibilizando para os alunos conteúdos e simulações que poderão ser utilizados de acordo com as necessidades e ritmos de aprendizagem. As reformas curriculares implantadas em escolas de enfermagem utilizando a metodologia ativa e participativa mudam o foco da aprendizagem do conteúdo para a aprendizagem significativa com foco no estudante e no mundo de trabalho. 
Consideramos que a avaliação clínica do Recém-nascido Pré-termo (RNPT) é um procedimento técnico essencial para a identificação do problema e o planejamento de seu cuidado. Durante esta avaliação, a criança fica exposta a temperatura ambiente e é manipulada por um período considerável, principalmente quando realizada por estudantes, seja pela riqueza de detalhes e achados, pelas dificuldades encontradas pelos mesmos ou pelo ir e vir até que o aprendizado se concretize. E que o ensino da avaliação clínica apresenta-se prejudicado pela inexistência de inovações que proporcionem uma ligação rápida e eficiente entre conhecimento teórico e prático.

Pensando nas inúmeras possibilidades do uso do computador na educação, em especial para suprir a lacuna existente pela escassez de materiais educativos e inovação no processo ensino-aprendizagem da temática semiologia do RNPT, sentimo-nos instigadas em desenvolver um software educacional para auxiliar no ensino da semiotécnica e semiologia nesta área. Este artigo tem como objetivo descrever o processo de desenvolvimento de um software educacional sobre semiotécnica e semiologia do RNPT. Esperamos ter como resultados, a produção de tecnologia inovadora de apoio à formação e educação permanente de enfermeiros sobre semiotécnica e semiologia do RNPT.

\section{MÉTODOS}

O desenvolvimento do software educacional foi fundamentada em referencial pedagógico, tendo por base a educação problematizadora de Paulo Freire.

A pedagogia problematizadora deve promover um processo de conscientização que ao mesmo tempo seja um ato de criação capaz de gerar outros atos de criação, e um veículo educacional no qual as pessoas são seres ativos. Esta educação problematizadora, ao contrário da educação bancária, implica num constante ato de desvelamento da realidade, buscando a emersão das consciências, resultando na inserção crítica do homem na realidade. Tem como objetivos a transformação social, a troca de experiências, o questionamento, a individualização e a humanização. Assim, a educação problematizadora compromete-se com uma programação, com conteúdos, que advém das colocações de sua existência, desafiando o educando a buscar respostas, tanto em nível de reflexão como de ação. Desse modo, busca-se juntos, educador e educandos, mediatizados pelo ambiente, pela realidade, o conteúdo a ser estudado. É sabido que todos os seres vivos aprendem por meio da interação com o ambiente. Todas as condutas se aprendem, e são aprendidas em um ambiente, e todos os ambientes têm capacidade de educar se soubermos percebê-los e nos relacionar com eles significativamente. ${ }^{6}$

Se um ambiente é um facilitador, por conseguinte, podemos afirmar que as técnicas pedagógicas também o são.

No ambiente digital de aprendizagem, os estudantes podem interagir facilmente com o conteúdo, que possibilita a rápida localização e a imediata disponibilidade de informações desejadas. Assim, os estudantes podem aprofundar-se num texto, conforme o interesse, as necessidades e o desejo. ${ }^{7}$

Para o desenvolvimento do software, foi utilizado um modelo proposto anteriormente, que apresenta quatro fases de desenvolvimento: 1. definição do escopo (pesquisa e brainstorming; definição do conteúdo e escopo; caracterização do usuário; análise da disponibilidade de recursos de hardware e software; elaboração inicial da interface; reunião dos recursos de mídia; aprovação da fase), 2. planejamento (organização do conteúdo; construção de fluxograma de apresentação; desenho da interface; planejamento cronológico; verificação de suporte financeiro e de recursos computacionais de hardware e software necessários e/ ou adicionais; prototipação; aprovação da fase), 3. produção e 4. implementação, o que facilita didaticamente a construção.

O projeto foi submetido à apreciação do Comitê de Ética em Pesquisa da Escola de Enfermagem de Ribeirão Preto da Universidade de São Paulo, sob o número de protocolo No $0334 / 2003$, sendo aprovado.

\section{RESULTADOS E DISCUSSÃO}

Este estudo é parte de um projeto maior, que tem como uma de suas temáticas de interesse a produção de conhecimentos e tecnologias dirigidas à educação em saúde de crianças e famílias, educação permanente e formação de enfermeiros para o cuidado ao neonato, criança e adolescente e suas famílias. Assim, temos desenvolvido e avaliado o uso de materiais didático-instrucionais como jogos, cartilhas e softwares educacionais. Pensando na Sistematização da Assistência de Enfermagem, o desenvolvimento deste software educacional auxilia no processo ensino-aprendizagem da 
primeira fase do Processo de Enfermagem, e em continuidade, estamos desenvolvendo outro software sobre o raciocínio para o Diagnóstico de Enfermagem.

No Processo de Enfermagem, o histórico de enfermagem é o momento em que o enfermeiro realiza a avaliação clínica do paciente, ${ }^{9}$ coletando os dados que serão de relevância na identificação do diagnóstico de enfermagem, fornecendo subsídios para um planejamento da assistência de acordo com as alterações das necessidades identificadas. ${ }^{10}$

A coleta de dados faz parte das funções e responsabilidades dos enfermeiros, pois é um dos requisitos fundamentais para a determinação do diagnóstico e prescrição de enfermagem, os quais estão determinados legalmente como atividades privativas, conforme consta na Lei $\mathrm{N}^{\circ} 7.498$, de 25.06.86, referente ao Exercício Profissional da Enfermagem, a qual determina que a Consulta de Enfermagem é atividade privativa do enfermeiro. ${ }^{11}$

Em 1994, houve a aprovação do novo currículo mínimo para os cursos de enfermagem, pela Portaria No 1721/94 do Ministério da Educação e Cultura, ${ }^{12}$ em que o conteúdo de semiotécnica e semiologia passa a ser obrigatório, com flexibilidade na forma de abordagem, podendo ser uma disciplina específica ou integrante de outra. ${ }^{13}$ Neste contexto, a semiotécnica e semiologia passam a integrar conteúdo específico nos cursos de graduação em enfermagem, como parte dos instrumentos básicos necessários para a assistência de enfermagem. Dentre os conteúdos ministrados no curso de graduação em enfermagem, o ensino da semiotécnica e semiologia é considerado fundamental, instrumentalizando o estudante na avaliação clínica e obtenção de dados essenciais para a sistematização do cuidado de enfermagem.

Desta forma, o ensino desse conteúdo deve proporcionar ao aluno de graduação em enfermagem base científica que fundamente os conhecimentos e técnicas especializadas correlacionando teoria à prática para realizar as atividades que são de sua responsabilidade.

Para isso, o parecer do Conselho Federal de Enfermagem $N^{\circ} 314 / 94,{ }^{14}$ da Portaria $N^{\circ} 1721$, de $15 / 12 / 94$, inclui conteúdos técnicos e metodológicos, meios e instrumentos necessários para que o aluno possa compreender os fenômenos que envolvem a semiotécnica e semiologia, de modo que ele reconheça e interprete sinais normais e de anormalidade significativos para o cuidado de enfermagem. ${ }^{9}$
Na fase de definição do escopo foi definido o objetivo da construção do software educacional, como o de auxiliar o estudante de graduação em enfermagem a desenvolver conhecimentos e habilidades necessárias sobre semiotécnica e semiologia do RNPT.

A necessidade de abordar este conteúdo, decorre do fato de ser fundamental para a formação do graduando em enfermagem pediátrica e neonatal, incluindo conteúdo extenso e complexo, ministrado por meio de aulas teóricas e práticas, sendo que nessa última estratégia formativa, os estudantes apresentam, inicialmente, inabilidade para avaliá-lo.

Além disso, o pré-termo não poder ficar exposto por períodos prolongados, nem ser excessivamente estimulado para o ensino da semiotécnica e semiologia; sua fragilidade biológica e especificidade geram nos alunos ansiedade, insegurança e medo de manipulá-lo, tornando o software uma aproximação precoce dos inúmeros achados durante a execução da avaliação clínica. Corroborou também, a necessidade de manipulação mínima de muitos destes bebês e a política de humanização da assistência nas unidades neonatais.

Alguns educadores têm procurado agregar novos conhecimentos em práticas de ensino e os recursos computacionais às práticas educativas. Ressalta a importância de o aluno ter contato com softwares educacionais durante sua formação, mas coloca como um dos obstáculos o número reduzido de programas computacionais desenvolvidos na língua portuguesa. ${ }^{15}$

A prática de desenvolvimento de instruções assistidas por computador, em países desenvolvidos, é intensa. ${ }^{16}$ No Brasil, apesar da escassez de material educativo computacional que pode auxiliar na ligação rápida da teoria à prática, o número de iniciativas de desenvolvimento tem se ampliado especialmente no presente século.

Assim, desde a decisão de desenvolver o material de ensino há a intenção de problematizar o contexto do processo ensino-aprendizagem da semiotécnica e semiologia do RNPT, numa tentativa de superar as barreiras que permeiam a temática, implicando num constante ato de desvelamento da realidade que conduziu-nos à reflexão e ação, procurando assim uma transformação da realidade. ${ }^{6}$

O conteúdo do software foi trabalhado de forma não-linear, o que aumenta a motivação dos alunos, a possibilidade de troca de informações e a interação entre os estudantes, também poten- 
cializa a liberdade intelectual, a flexibilidade e a criatividade de navegar por diferentes caminhos e construir seus conhecimentos de forma ativa, respeitando o ritmo próprio de cada indivíduo. Pressupostos estes da educação problematizadora.

A educação bancária se sustenta a partir de uma lógica linear de adoção e recepção do conhecimento, oposta a educação problematizadora. ${ }^{6}$

Durante o período em que desenvolvemos o software, acompanhamos os estudantes de graduação em enfermagem nas atividades teóricopráticas nas unidades neonatais. As dúvidas, dificuldades e anseios expressos por estes alunos ao realizarem a avaliação clínica dos bebês prétermo ajudaram substancialmente na construção do software educacional, bem como os apontamentos e sugestões feitas por eles nas avaliações da disciplina acerca dos conteúdos que deveriam ter sido mais explorados.

Assim, a seleção do conteúdo foi realizada, dentre outras fontes, com o auxílio dos agentes envolvidos no processo ensino-aprendizagem da temática. Isso nos remete a um dos pressupostos da educação problematizadora, a participação dos agentes na construção de seus conhecimentos, na troca de experiências e no questionamento sobre a sua realidade. ${ }^{6}$

Assim, o conteúdo do software foi organizado em quatro partes: 1 . apresentação, incluindo também justificativa, objetivo e lista de abreviações; 2. semiotécnica, contendo conceitos teóricos e práticos das técnicas de inspeção, palpação, percussão e ausculta utilizadas na avaliação clínica do pré-termo; 3. semiologia, abordando conceitos, histórico, contexto (recém-nascido pré-termo, avaliador, ambiente e família) e os tipos de avaliação (ao nascimento, de transição e sistemática). A avaliação clínica sistemática foi trabalhada por necessidades humanas básicas (oxigenação, circulação, termorregulação, alimentação e hidratação, eliminação, integridade tecidual, sono e repouso, sexualidade, percepção sensorial, psicossocial e psicoespiritual), aspecto inédito na organização do conteúdo didático e ensino dos estudantes de enfermagem. Na literatura, este conteúdo apresenta-se organizado por sistemas ou céfalo-caudal; 4. simulações, com questões de múltipla escolha e respectivos feedback de resposta certa ou errada, visando testar os conhecimentos adquiridos com o uso do software. As 143 questões formuladas são apresentadas em sequência aleatória, considerando-se que houve aprendizado adequado quando o estudante acertar pelo menos $70 \%$ das questões.
O software contém, ainda, links, referências, ficha técnica e galeria (banco de mídias).

As simulações apresentam os problemas existentes nas experiências cotidianas do aprendiz ao realizar a avaliação clínica do pré-termo, buscando a inserção crítica deste estudante na sua realidade, estimulando a reflexão e ação. ${ }^{6}$

Nas simulações do software educacional estão presentes situações do cotidiano e os usuários levantam hipóteses e escolhem alternativas que julgam mais adequadas aos problemas apresentados. O feedback do aprendizado, nas simulações, é também uma estratégia da educação problematizadora.

A utilização do software pode ocorrer em qualquer lugar que disponha de computador, como sala de aula, laboratório de informática, hospital e domicílio, pois está disponibilizado em CD-ROM, bem como, nos diferentes períodos do curso de graduação e momentos da profissão, pois o aprofundamento no conteúdo será de acordo com o desejo da descoberta e a necessidade dos envolvidos no processo, para que seja significativo para eles.

Na fase de planejamento, o conteúdo nos tópicos foi sendo gerado e organizado partindo dos conteúdos mais gerais até os mais específicos, finalizando com os conteúdos de apoio para avaliação clínica.

A informação visual e estética tem o objetivo de facilitar a aprendizagem, usa efetivamente, a comunicação não verbal incluindo sinais emocionais que motivem, dirijam ou distraiam. A organização da informação tanto pode auxiliar o usuário como confundi-lo. Dependendo da organização da informação, de sua apresentação, até a funcionabilidade da tela pode ser afetada. Um layout adequado tem uma função muito maior que simplesmente decorativa, todas as informações visuais influenciam umas nas outras e dependem do contexto a que estão inseridas. ${ }^{17}$

Todas as telas do software têm a mesma estrutura funcional, com distribuição de ícones e de cores, assim, a cor branca foi utilizada no fundo da tela, verde no título, vermelho no subtítulo e azul e preto no texto. A escolha das cores está em consonância com a recomendação de uma cor neutra para o fundo, pois aumenta a visibilidade das outras cores e torna o texto mais legível, ao contrário de cores muito escuras no fundo que aumentam o cansaço visual. É, recomendado também, cores monocromáticas para o texto, sempre que possível. ${ }^{17}$ 
Na tela inicial do software, na Figura 1, para iniciar a navegação, o usuário deve clicar sobre a figura central, conforme apontado na parte inferior, a fim de obter o acesso aos menus, ícones e ferramentas, motivo pelo qual esses estão com menor destaque (menos iluminado). Por outro lado, caso o usuário não atenda essa dinâmica de interação, o programa a efetuará automaticamente em 15 segundos.

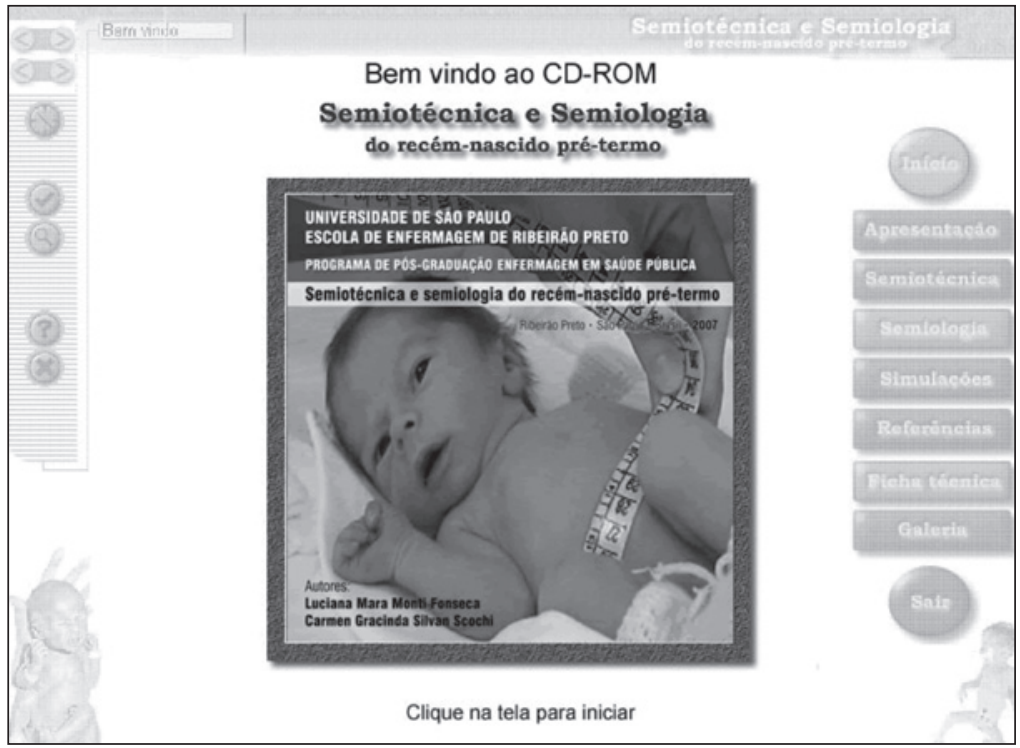

Figura 1 - Tela de entrada do software educacional semiotécnica e semiologia do recém-nascido pré-termo, com menu principal à direita e outro à esquerda

A partir desta tela, o usuário visualiza na lateral direita, o menu principal e, além deste, a equipe de desenvolvimento criou um à esquerda, em todas as telas, que contém botões que facilitam a navegação, como seção anterior e próxima seção; página anterior e próxima página; menu; início; procura; ajuda e saída. Na parte inferior das telas, Figura 2, há a barra de acesso aos conteúdos complementares, dentre outros.

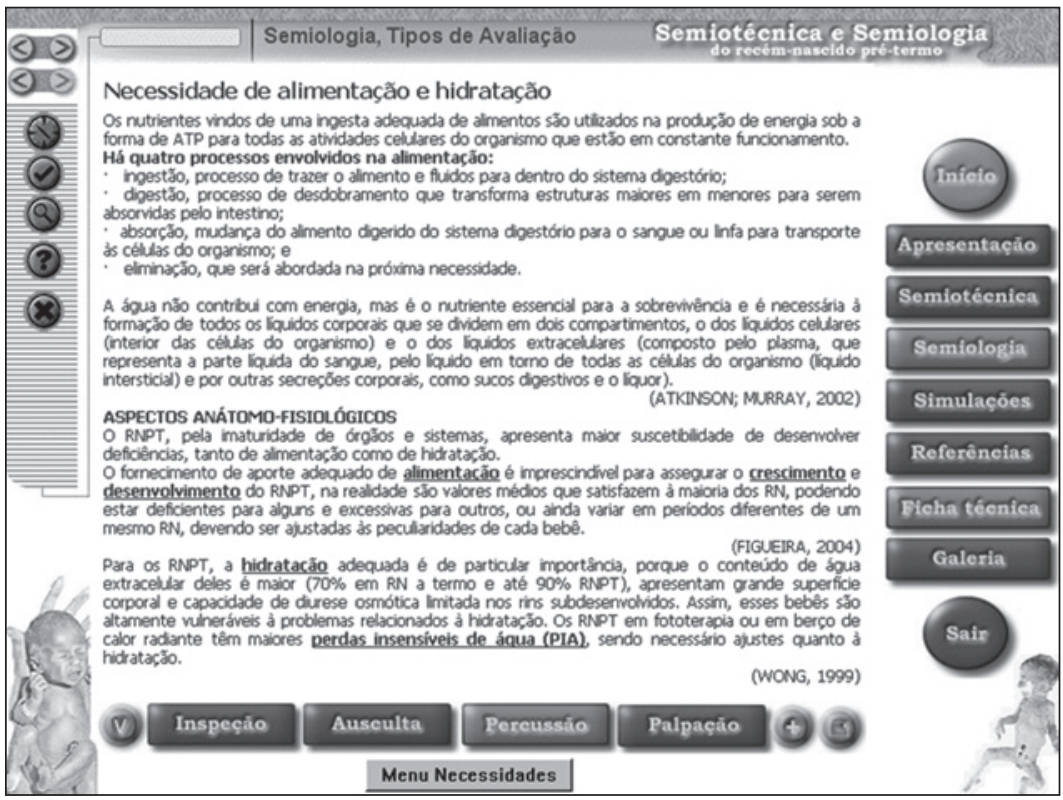

Figura 2 - Barra de acesso aos conteúdos complementares na parte inferior da tela do software educacional 
No menu à esquerda, Figura 3, há um ícone de procura (caracterizado por uma lupa) contendo a base de dados, o qual ao ser clicado conduz a uma ja- nela em que o usuário, ao digitar uma palavra, vêno sistema todas as telas que a palavra procurada está presente e como ir até estes locais, se solicitado.

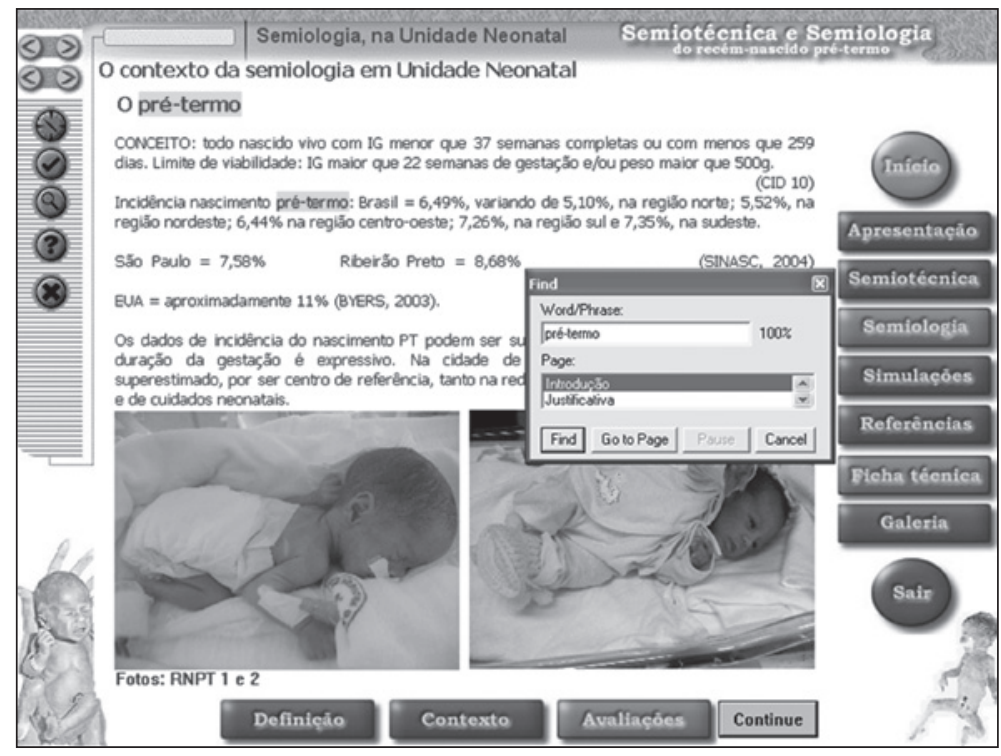

Figura 3 - Ferramenta de procura por palavras-chave no menu à esquerda no software educacional

Pensando em materiais educacionais que colaborem no sentido de um processo ensinoaprendizagem mais ativo, encontramos três softwares educacionais que incluem conteúdos de semiotécnica e semiologia do adulto ${ }^{18}$, lactente ${ }^{19}$ e recém-nascido a termo. ${ }^{20}$

Um estudo desenvolveu multimídia interativa como recurso no ensino de semiologia para os estudantes de enfermagem. ${ }^{18} \mathrm{O}$ autor constatou que a multimídia é fácil de manusear e facilita a inter-relação dos conteúdos teóricos e a prática da semiologia, pois aumenta a compreensão das aulas e inova o ensino, auxiliando no exame físico direto no paciente. Ao utilizar o CD-ROM com alunos de graduação em enfermagem, verificou que o uso da multimídia interativa, como estratégia de ensino-aprendizagem direcionada à semiologia cardíaca, respiratória, da pele e do sistema neurológico, propiciou um repensar das práticas ou paradigmas pedagógicos.

Pesquisa semelhante desenvolveu e validou um software educacional sobre a consulta de enfermagem em puericultura, enfocando o exame físico do lactente sadio, para ser utilizado por professores e alunos de graduação em enfermagem, bem como na educação permanente da equipe de enfermagem. ${ }^{19}$ Utilizaram uma metodologia de desenvolvimento de software educacional ${ }^{8}$ e o software de autoria Director ${ }^{\circledR}$. Os resultados ressaltaram a importância da participação efetiva de professores das áreas de enfermagem e educadores, analistas de sistemas, experts na área do conteúdo educacional e estudantes, no desenvolvimento e validação do software. O produto foi classificado como muito bom, por alunos e professores, e bom, por analistas. As autoras recomendam novas pesquisas, com outros conteúdos, para se oferecer aos alunos um acervo de softwares educacionais desenvolvidos pelos profissionais das disciplinas correspondentes.

Salientamos ainda, um software educacional sobre o exame físico do recém-nascido a termo, por meio de módulos auto-instrucionais. ${ }^{20} \mathrm{~A}$ construção dos módulos foi baseada na teoria da aprendizagem de Gagné e estruturados no plano Keller e no enfoque sistêmico, sendo adaptados conforme a proposta de instrução assistida por computador de Prince. Foi utilizado o programa Power Point $2000^{\circledR}$ para o desenvolvimento do software, o qual foi avaliado por 11 peritas da área de enfermagem neonatológica, que emitiram os conceitos bom e excelente para os 42 itens. As autoras consideram que esse software educacional pode contribuir com os docentes de enfermagem neonatológica e com o crescimento e autodesenvolvimento do graduando no aprendizado do exame físico do neonato, além de transformar aulas tradicionais em aulas mais dinâmicas, incentivando a participação ativa do aluno na construção de seu conhecimento. 
Constatamos que cada um dos softwares apresenta uma característica que o difere dos demais. Alguns utilizam apenas um tipo de mídia, outros um conjunto composto por mídias diferentes; são desenvolvidos com metodologias diferentes e alguns não integrados com um referencial pedagógico, outros usaram diferentes referenciais.

Apesar de estes softwares terem sido desenvolvidos e validados junto ao estudante de enfermagem, eles não proporcionam uma entrada fácil e rápida no programa, visto que não é autoexecutável. Apresentam uma estrutura não flexível impossibilitando que o usuário navegue pelo caminho que quiser, nesse último, o usuário necessariamente passa por um módulo, faz os exercícios e só se acertar $70 \%$ dos testes é que consegue passar para o módulo seguinte e assim, sucessivamente. ${ }^{20}$

$\mathrm{Na}$ tentativa de avançar nestas questões, o software educacional semiotécnica e semiologia do RNPT é auto-executável, diferentemente dos softwares anteriores, que requer instalação, podendo causar no usuário sensação de impotência e desconhecimento frente à tecnologia utilizada. Os menus nas telas do software foram construídos pensando em possibilitar que o usuário navegue livremente, numa estrutura não-linear e flexível. Acreditamos que a possibilidade do usuário ir para onde deseja, no software, aumenta seu interesse e estimula o aprendizado.

Para o desenvolvimento do software contamos com financiamento de agências de fomento, que possibilitou-nos a aquisição de equipamentos, tais como microcomputador, monitor, scanner, impressora laser, impressora jato de tinta, gravadora de CD-ROM, microfone, mouse, filmadora digital e câmera digital, Placa Capt Liquid Edition; de softwares Macromedia Authorware ${ }^{\circledR}$ e Macromedia Studio $M X^{\circledR}$, Norton Antivirus ${ }^{\circledR}$; Windows Xp Home Edition Brasilian Upgrade Microsoft; além da contratação de empresa especializada em programação e arte final.

Na fase de produção, os esboços finais (layouts de tela) foram organizados. O formato da interface tornou-se definitivo e padronizado. As mídias já intituladas e editadas, anteriormente, foram organizadas em um banco de dados que denominamos "galeria".

Assim, o software de autoria Authorware ${ }^{\circledR}$ apresenta um total de $390 \mathrm{Mb}$, sendo $50 \mathrm{Mb}$ utilizados para o módulo texto; $30 \mathrm{Mb}$, simulações; $6 \mathrm{Mb}$, galeria; $140 \mathrm{Mb}$, fotos; $24 \mathrm{Mb}$, figuras; $135 \mathrm{Mb}$, vídeos; $5 \mathrm{Mb}$, sons, com tempo estimado de 25 horas de navegação.
A validação do conteúdo e aparência, parte da fase de implementação, foi realizada junto a cinco especialistas da área tecnológica (dois técnicos em informática e três técnicos em áudio-visual) e 11 profissionais da área de enfermagem, (cinco docentes de enfermagem pediátrica e neonatal, semiologia em enfermagem e informática em enfermagem e seis enfermeiras assistenciais de unidades neonatal e pediátrica), que atenderam ao critério de inclusão: cinco anos ou mais de experiência em suas áreas de atuação ou título de especialista. Elaboramos três instrumentos diferentes para os profissionais de informática, de audiovisual e de enfermagem, fundamentados em outros estudos relacionados a softwares educacionais. Os instrumentos incluíram, ainda, o método somativo, escala do tipo Likert. A grande maioria dos itens avaliados no software recebeu conceitos bom e muito bom de mais de $70 \%$ dos avaliadores, sendo, portanto, validado sua aparência e seu conteúdo. Exceção ocorreu no item qualidade da interface que obteve proporção menor do que o estabelecido para esse conceito, mas foram feitas as correções dos problemas técnicos apresentados no software e incorporada grande parte das sugestões emitidas pelos avaliadores. ${ }^{21}$

Com relação às tarefas de implantação, revisão pós-implantação e distribuição da fase de implementação, não fizeram parte deste estudo e serão contempladas em estudos posteriores.

O uso de recurso tecnológico nas atividades acadêmicas deve estar em consonância com um projeto político-pedagógico renovado, embasado no currículo por competência e integrado, que articula a formação ao mundo do trabalho e que utiliza pedagogias crítico-reflexivas, na qual os estudantes têm papel ativo na construção de seus conhecimentos.

A utilização da tecnologia no processo de ensino-aprendizagem está plenamente justificada se levarmos em conta que um dos objetivos básicos da educação é preparar os estudantes para serem cidadãos de uma sociedade plural, democrática e tecnologicamente avançada. ${ }^{22}$ Assim, o uso da tecnologia precisa ser mantido constante dentro da escola. Atualmente, em nossa sociedade, não há mais como separar a tecnologia e suas estreitas relações com e na educação, estando seu uso em consonância com as novas propostas na educação, pois o ensino tradicional, pouco dinâmico, nem sempre oferece a experiência real e a ligação teoriaprática possibilitado pelo computador.

O enorme crescimento na demanda por habilidades e conhecimentos especializados em 
enfermagem, a tendência a um maior uso de tecnologias médicas sofisticadas e a carência de profissionais com experiência suficiente nessas novas áreas têm influenciado as mudanças na educação em enfermagem nas últimas décadas. ${ }^{19}$

É inegável a contribuição do uso dos materiais educativos na educação em enfermagem. Com o intuito de fortalecer a prática educativa da enfermagem, o enfermeiro no seu papel de educador deve envolver-se além da utilização da tecnologia como instrumento didático, no processo de criação, desenvolvimento e avaliação da tecnologia educativa. ${ }^{23}$

O uso da tecnologia na educação em enfermagem deve ser pensado junto às metodologias ativas de aprendizagem que se propõem a substituir a memorização e a simples transferência de informações e de habilidades, pela construção do conhecimento a partir da vivência de situações reais ou simuladas da prática profissional, estimulando as capacidades de análise crítica e reflexiva e o aprender a aprender. Assim o software educacional desenvolvido vem somar esforços nesta direção.

\section{CONSIDERAÇÕES FINAIS}

O desenvolvimento do software educativo exigiu empenho educacional, tecnológico e científico num compromisso a longo prazo.

Mais que oferecer um conteúdo sobre a semiotécnica e semiologia do RNPT, agregamos aspectos referentes ao próprio desenvolvimento do software, que congrega, além do uso de recursos tecnológicos interativos, a organização do conhecimento sobre a semiotécnica e semiologia do RNPT e a elaboração de simulações acerca destes conteúdos para aferir o aprendizado dos usuários (estudantes e enfermeiros). Outra inovação apresentada é a reorganização do conteúdo da semiologia do prematuro em necessidades humanas, diferentemente da literatura disponível que apresenta a avaliação clínica na sequência céfalo-caudal ou por sistemas.

Embora este software educacional tenha como principal usuário o estudante de graduação em enfermagem e o enfermeiro, na formação e na educação permanente, ele também pode ser utilizado por estudantes e profissionais das áreas afins, que se utilizam da avaliação clínica em sua prática profissional.

Assim, consideramos que o produto desenvolvido está adequado para ser disponibilizado para uso no ensino de enfermagem sobre a semiotécnica e semiologia do prematuro, cuja implantação será avaliada em estudos posteriores, juntamente com a atualização de conteúdos e incremento de outros recursos de mídia conforme sugestões dos avaliadores.

Por intermédio das estratégias problematizadoras, o software não apresenta uma sequência rígida, não é linear. O conteúdo foi selecionado priorizando as colocações dos agentes envolvidos no processo ensino-aprendizagem da temática em questão, e as simulações apresentam experiências cotidianas do aprendiz, para que ele possa fazer escolhas e tenha feedback do seu aprendizado.

Consideramos que este software apresenta a possibilidade de um ensino inovador para mediadores e estudantes que vislumbram trabalhar, concomitantemente, o conteúdo de semiotécnica e semiologia do RNPT, abordagens pedagógicas mais ativas, inovações tecnológicas em educação e a organização do conteúdo em necessidades humanas básicas.

As experiências existentes tanto no desenvolvimento quanto na utilização de tecnologias no ensino na área da saúde, e em especial, na Enfermagem, nos remete à necessidade de avaliar, não apenas os produtos tecnológicos construídos, mas também no que estes têm contribuído para o processo ensinoaprendizagem, tendo como foco o seu impacto.

Precisamos ir além do desenvolvimento de materiais educacionais, assim, em continuidade a este estudo temos a responsabilidade e o compromisso, enquanto pesquisadores do Grupo de Pesquisa em Enfermagem no Cuidado à Criança e ao Adolescente da EERP/USP, de validar o software educacional Semiotécnica e semiologia do recém-nascido pré-termo junto à principal população alvo, os estudantes de enfermagem, e avaliar o impacto de seu uso no processo ensinoaprendizagem, inserido na abordagem da educação problematizadora.

\section{REFERÊNCIAS}

1. Moran JM, Masetto MT, Behrens MA. Novas tecnologias e mediação pedagógica. Campinas (SP): Papirus; 2006.

2. Chaves EO. O computador na educação [página na internet]. [atualizado 2004 Mai 02] [acesso 2007 Set 02]. Disponível em: http://www.chaves.com.br/ TEXTSELF/EDTECH/funteve.htm

3. Zem-Mascarenhas SH, Cassiani SHB. A criança e o medicamento: software educacional sobre administração de medicamentos em pediatria. Rev Bras Enferm. 2000 Jul-Ago; 53(4):499-507. 
4. Rouse DP. Creating an interactive multimedia computer-assisted instruction program. Comput Nurs. 1999 Jul-Aug; 17(4):171-6.

5. Padalino Y, Peres HHC. E-Learning: estudocomparativo da apreensão do conhecimento entre enfermeiros. Rev Latino-am Enfermagem. 2007 Mai -Jun; 15(3):397-403.

6. Freire P. Pedagogia do oprimido. Rio de Janeiro (RJ): Paz e Terra; 2004.

7. Wingert B. Hypertext - das elektronische Buch. Das Magazin. 1992; 3(2):28-9.

8. Bernardo V. Metodologia para desenvolvimento de projeto multimídia aplicado ao ensino da medicina [dissertação]. São Paulo (SP): Universidade Federal de São Paulo. Escola Paulista de Medicina; 1996.

9. Luizari MRF. Exame físico na criança: uma contribuição para o ensino de semiologia na enfermagem [dissertação]. São Paulo (SP): Universidade Federal de São Paulo. Escola Paulista de Medicina; 2000.

10. Sousa VD, Barros ALBL. O ensino do exame físico em escolas de graduação em enfermagem do município de São Paulo. Rev Latino-am Enfermagem. 1998 Jul; 6(3):11-22.

11. Brasil. Lei $N^{o} 7.498$, de 25 de junho de 1986. Dispõe sobre o exercício da enfermagem e dá outras providências. Diário Oficial da República Federativa do Brasil, 26 Jun 1986. Seção 1.

12. Brasil. Ministério da Educação e do Desporto. Portaria $N^{\circ} 172$, de 15 de dezembro de 1994. Dispõe sobre a formação do enfermeiro de graduação. Diário Oficial da República Federativa do Brasil, 16 Dez 1994. Seção 1.

13. Dias MAS, Machado MFAS, Silva RM, Pinheiro AKB. Vivendo uma proposta emancipatória no ensino de semiologia para a enfermagem. Rev Latino-am Enfermagem. 2003 Mai-Jun; 11(3):364-70.

14. Brasil. Ministério da Educação e Cultura. Conselho Federal de Educação. Parecer No 314/94. Currículo mínimo para o curso de enfermagem. Brasília (DF); 1994.

15. Marin HF. Informática em enfermagem. São Paulo (SP): EPU; 1995.

16. Jeffries PR. Development and test of a model for designing interactive CD-ROMS for teaching nursing skills. Comput Nurs. 2000 May-Jun;18(3):118-24.

17. Parizotto R. Elaboração de um guia de estilos para serviços de informação em ciência e tecnologia via Web [dissertação]. Florianópolis (SC): Universidade Federal de Santa Catarina. Programa de Pósgraduação em Engenharia de Produção; 1997.

18. Santiago LC. A multimídia interativa como recurso didático-pedagógico para o ensino teórico-prático da semiologia em enfermagem [tese]. Ribeirão Preto (SP): Escola de Enfermagem de Ribeirão Preto da Universidade de São Paulo; 2003.

19. Motta MCS, Marin HF, Zeitoune RCG. Desenvolvimento do software educacional em saúde do lactente. Rev Enfermagem Esc Anna Nery. 2001 Ago; 5(2):211-23.

20. Fernandes MGO, Barbosa VL, Naganuma M. Exame físico de enfermagem do recém-nascido a termo: software auto-instrucional. Rev Latino-am Enfermagem. 2006 Mar-Abr; 14(2):243-50.

21. Fonseca LMM, Leite AM, Mello DF, Dalri, MCB, Scochi CGS. Semiotécnica e semiologia do recémnascido pré-termo: avaliação de um software educacional. Acta Paul Enferm. 2008 Jun; 21(4):543-8.

22. Maiztegui A, Acevedo JÁ, Caamaño A, Cachapuz A, Cañal P, Carvalho AMP, et al. Papel de la tecnología en la educación científica: una dimensión olvidada. Rev Iberoamericana de Educación [online]. 2002 Ene-Mar [acesso 2008 Abr 10]; 28: 129-55. Disponível em: http:/ / www.rieoei.org/rie28a05.htm

23. Oliveira MS, Fernandes AFC, Sawada NO. Manual educativo para o autocuidado da mulher mastectomizada: um estudo de validação. Texto Contexto Enferm. 2008 Jan-Mar; 17(1):115-23. 